\title{
Who Are the Victims of Cyberbullying? Preliminary Data Towards Validation of "Cyberbullying Victim Questionnaire"
}

\author{
Mirian Agus \\ Department of Pedagogy, Psychology, Philosophy, Faculty of Humanistic Studies, University of Cagliari, Italy \\ ORCID: 0000-0001-6774-1530 \\ Maria Lidia Mascia \\ Department of Pedagogy, Psychology, Philosophy, Faculty of Humanistic Studies, University of Cagliari, Italy
} ORCID: 0000-0002-1998-4818

Maria Assunta Zanetti

Department of Brain and Behavioural Sciences, University of Pavia, Italy

ORCID: 0000-0002-5185-0270

Simona Perrone

Istituto Comprensivo "Renato Moro", Taranto, Italy

ORCID: 0000-0002-2620-0727

Dolores Rollo

Department of Medicine and Surgery, University of Parma, Italy

ORCID: 0000-0003-2506-2999

Maria Pietronilla Penna

Department of Pedagogy, Psychology, Philosophy, Faculty of Humanistic Studies, University of Cagliari, Italy ORCID: 0000-0002-0982-3893

\begin{abstract}
In the literature there are more and more works dealing with cyberbullying and adolescents' perception of this phenomenon. In particular, we are interested in cyberbullying and the effects of cyberbullying on adolescent life. What is more, in 2020 the impact of COVID-19 has increased the digital presence of cyberbullying behaviours. This phenomenon is extremely complex, since it is multicomponential and multifactorial, and many components act on it. Starting with an analysis of the literature, this work offers preliminary data towards the validation of a self-reporting questionnaire; it was administered to 650 adolescents, to evaluate their perceptions of the victims of cyberbullying. The questionnaire consisted of 33 items; Principal Component Analysis was applied, which identified the dimensions resuming the items' variability. The findings confirmed the multidimensional nature of the issue covered by the questionnaire and highlighted three psychological dimensions: Internalisation, Counterbalance and Marginalisation. The results support the structure of the questionnaire, useful to quickly collect information about adolescents' perception of cybervictimisation. The assessment of this information might help teachers, educators, and tutors to formulate targeted interventions to combat the spread of cyberbullying aimed for example at improving emotional intelligence, starting from the construction of emotional contagion.
\end{abstract}

Keywords: cyberbullying, adolescent representations, cybervictims, assessment 


\section{INTRODUCTION}

While the Internet has its benefits, there has been much speculation as to whether the Internet may also be harmful to social and psychological well-being (Kraut et al., 1998; Marchant et al., 2017; Twenge et al., 2019). Although digital communication has some indisputable and acknowledged advantages (Gross et al., 2002), these can easily turn negative and lead to risky situations (Sabella et al., 2013).

The significant advantages offered by the Internet may be accompanied by risks and dangers which children and young people often fall victim to, especially digital natives. Digital natives are significant users of new technologies who are however often unaware of the difficulties posed by the Internet (Hinduja \& Patchin, 2013; Lareki et al., 2017). Often even adults (digital immigrants) are not fully aware of the risks associated with the use of the Internet and new technologies.

In particular, with the more pervasive use of technology, the phenomenon of cyberbullying has also increased (Ansary, 2020; Aoyama, 2011; Watts et al., 2017). According to the literature (Jain et al., 2000), cyberbullying is a continuing trend mainly among adolescents and young adults. What is more, in 2020 the impact of COVID19 has increased individuals' digital presence and it is speculated that the pandemic has triggered a significant rise in cyberbullying.

Cyberbullying has been designated as a serious public health problem, which can dramatically affect the lives of adolescents (Palladino et al., 2017).

Cyberbullying has some specific features:

- Anonymity: Victims may not know the identity of their persecutor: only $40-50 \%$ of the victims of cyberbullying know the identity of the perpetrator: This anonymity can cause victims to feel frustrated and helpless (Barlett, 2017; Huang \& Chou, 2010; Wang \& Ngai, 2020).

- Speed of dissemination of information: Large audiences are often involved, and victims are unable to remove content after it has been shared online. Many actions in the virtual world are public, and more serious actions often reach a wider audience. Cyberbullying reaches a wider group of victims via cyber platforms (Casas et al., 2013; Palladino et al., 2017; Selkie et al., 2016).

- Lack of face-to-face confrontation between bully and victim/Invisibility: These interactions lack the expressive feedback typical of face-to-face interactions. This absence of visual signals combined with written communication can change people behavior and make them less aware of what they are doing.

- Parental control: Lack of adequate parental supervision may also contribute to cyberbullying. Ybarra and Mitchell (2004) found that respondents identified as cyberbullies lack adequate parental supervision. Wang and colleagues (2019) found that adolescents with high levels of parental supervision and support reported less engagement in bullying and cyberbullying. This finding suggests that positive parental conduct or actions safeguard children from participating in bullying.

Therefore, in cyberbullying, the relationship between the bully and the victim takes on dynamics that in some way differ from face-to-face bullying (Dredge et al., 2014). Starting from this analysis, the focus of this paper is on the role and adolescent's representation of the victim of cyberbullying.

Indeed, we support the idea that through an analysis of the victims' perception among adolescents, it is possible to prepare targeted interventions, adapted to these virtual scenarios.

In particular, it is more important to focus attention on this aspect, because sometimes there is a tendency to downplay the victim's role and their features; this fact may lead to dangerous consequences related to the underestimation of the effects of cyberbullying behaviour.

The focus of this work is on carrying out a preliminary analysis aimed at validating a tool that detects the adolescents' representation of cybervictims. It is essential to have data collection tools that are quick and easy to administer, but at the same time, that immediately grasp what dimensions need to be addressed, 
which dimensions should be taken into account, on which dimensions educational and psychological action can be implemented to combat the worrying spread of cyberbullying.

Such a tool is also essential to understand how much in the adolescents the victim's representation deviates from reality or is influenced by false beliefs.

Studies in literature state that cybervictims experience internalised suffering, such as depression, anxiety and low self-esteem, insecurity, thoughts of suicide, loneliness, low school success, drug addiction, somatic symptoms, and low self-confidence (Dredge et al., 2014; Ladd et al., 2017; Şahin et al., 2012). They often have an overprotective family background or adverse family environments (Lereya et al., 2013) or lack family support (Shaheen et al., 2019), and they may experiencesnumerous social difficulties such as peer rejection or poor peer acceptance (marginalisation) (Mishna et al., 2020).

In the literature it is highlighted that sometimes there is a significant relationship between cyberbullies and cybervictims, and the borders between them are unclear and transitive in structure (Durak \& Saritepeci, 2020). The phenomenon of duality is prevalent in cyberbullying, whereby an individual assumes two completely opposite roles, i.e., being at once the cybervictim and a the cyberbully (Lozano-Blasco et al., 2020). Hence, preventive interventions have to be envisaged starting from the cybervictim, in order to act immediately in an educative way among children and adolescents. This aspect of duality (being alternatively cybervictim and cyberbully) highlights even more the importance of knowing the representations that adolescents have of the cybervictim, in order to implement ad hoc interventions to support a greater awareness by adolescents of the discomforts and difficulties experienced by the victim. In this way, educators will be able to act at a primary prevention level.

\section{METHOD}

\section{Participants}

A total of 650 students ranging from $12-16$ years old $(M=13.2, S D=2.5$ ) enrolled in high school grades I, II, and III in Sardinia took part in the study. The study was approved by the institutional committees of the schools in which the survey was administered and by the ethics committee of the University. All students received informed consent to participate from their parents. The sample was composed of an almost equal ratio of females to males (306 males, 47.1\%). Participants were all Italian, and their SES was based on parents' education and careers (see Table 1). They live in small towns with fewer than 15,000 inhabitants. Participants were recruited as part of a larger study on the phenomenon of cyberbullying. Nine students were excluded because they failed to complete the protocol. The non-probability sampling technique was used on the basis of four social variables: age, gender, school grade, and place of residence. Participants stated that they spent an average of 5 hours per day online on working days ( $M=5.13, S D=4.02)$ and holidays $(M=5.30, S D=4.25)$. As self-reported by the participants, $7.5 \%$ of them had been cybervictims, $1.6 \%$ had been cyberbullies, and $3.9 \%$ had been both victims and aggressors.

Table 1 shows the demographic statistics.

\section{Measures and Procedure}

The measures consisted of a paper-and-pencil questionnaire, which included demographic questions (related to age, gender, ethnicity, and residence). A specific question (on a nominal scale) was included in the introductory part of the questionnaire, aimed at investigating the first-hand experience of the teenager about cyberbullying. This question asked: "Have you ever experienced cyberbullying?" (a) "Yes, I have been the victim of CB"; (b) "Yes, I have been a cyberbully"; (c) "I have been both cyberbully and cybervictim"; (d) "No, I have never experienced cyberbullying". The answer given to this question allows us to assign adolescents to following specific groups: victim, cyberbully, bully/victim (both), no experience of cyberbullying (see Table 1). 
Table 1. Demographic data and descriptive statistics for the inquired dimensions

\begin{tabular}{|c|c|c|}
\hline & $\mathrm{Fr} \%$ & Mean (sd) \\
\hline \multicolumn{3}{|l|}{ Gender } \\
\hline Female & $47.1 \%$ & \\
\hline Male & $52.9 \%$ & \\
\hline Age & & $13.2(2.5)$ \\
\hline \multicolumn{3}{|l|}{ Educational level - mother } \\
\hline Completed primary schools & $13.7 \%$ & \\
\hline Completed secondary schools - first level & $27.8 \%$ & \\
\hline Completed secondary schools - second level & $34.8 \%$ & \\
\hline Graduate & $20.5 \%$ & \\
\hline Post-graduate & $3.2 \%$ & \\
\hline \multicolumn{3}{|l|}{ Educational level - father } \\
\hline Completed primary schools & $15.2 \%$ & \\
\hline Completed secondary schools - first level & $34.3 \%$ & \\
\hline Completed secondary schools - second level & $33.4 \%$ & \\
\hline Graduate & $14.8 \%$ & \\
\hline Post-graduate & $2.3 \%$ & \\
\hline \multicolumn{3}{|l|}{ Adolescent's experience of cyberbullying } \\
\hline Victim & $7.5 \%$ & \\
\hline Cyberbully & $1.6 \%$ & \\
\hline Bully / Victim & $3.9 \%$ & \\
\hline No experience of Cyberbullying & $87.1 \%$ & \\
\hline
\end{tabular}

The items analysed in this study were part of a larger protocol of research assessing the dimensions related to adolescents' life.

The self-reported items regarding the perceptions of cybervictim among adolescents, investigated specific themes defined and based on previous relevant works in the literature (Kowalski et al., 2014; Renati et al., 2012). The formulation and lexical construction of the items was carried out through careful discussion and analysis by a pool of researchers experienced in the topic of cyberbullying.

The questionnaire was characterised by 33 items on a 5-point Likert scale (from 1 - never to 5 - always) investigating personal factors (perceptions, values, maladaptive behaviours), routes and present internal states (affect, cognition, arousal), aspects related to decision making (thoughtful and impulsive action), and distal outcomes (regarding physical and psychological health, social functioning, and behavioural problems) (Kowalski et al., 2012).

The items presented are shown in Table 3 and discussed in the following section.

\section{RESULTS}

According to the answers given by adolescents to the specific question, we found that $7.5 \%$ of the participants have had a personal experience as cybervictims, $1.6 \%$ as cyberbully, 3.9\% as both (cyberbully / cybervictim), and $87.1 \%$ have had no direct personal experience of cyberbullying (see Table 1).

To carry out the preliminary assessment of the psychometric features of the devised questionnaire, a Principal Component Analysis (PCA) with non-orthogonal Oblimin rotation, was conducted on the items of the questionnaire (Tabachnick \& Fidell, 1996). To identify the components, the criteria defined by Kaiser were considered: a) eigenvalues greater than 1 ; b) each component explaining a minimum of $5 \%$ of the variance; c) unique loadings greater than or equal to 0.40 ; d) a good value for the Kaiser-Meyer-Olkin (KMO) measure. Including the 33 items, a simple solution with three components was identified, accounting for $34.72 \%$ of the total variance. They represent Internalisation, Counterbalance, and Exclusion/Marginalisation. The values of saturation and reliability are reported in Table 2. 
Table 2. Results of application of Principal Component analysis - Variance explained by components (Rotation Method: Oblimin with Kaiser Normalization)

\begin{tabular}{lcccc}
\hline Component & \multicolumn{2}{c}{ Extraction Sums of Squared Loadings } & \multicolumn{2}{c}{ Rotation Sums of Squared Loadings } \\
\hline 1 & Total & \% of Variance & Cumulative \% & Total \\
2 & 6.331 & 19.185 & 19.185 & 5.728 \\
3 & 2.929 & 8.875 & 28.060 & 2.677 \\
\hline
\end{tabular}

The first component (represented by 17 items) in Internalisation, regarding the consequences that cyberbullying has on victims' lives, including dysfunctional behaviours such as destructive and suicidal thinking, social isolation, depression and other negative manifestations of suffering such as loss of appetite, life deprivation, and psychoactive and drug/substance abuse. Similar conduct may often be seen in reactive behaviours like aggression and violence toward the people surrounding the victim or negative feelings that discredit their own emotions and act as a self-threat. The latter feelings include low self-esteem, guilt, shame, and helplessness. In a sense, perceiving themselves as cybervictims is enough to justify and accept oppression and tyranny.

The second component ( 6 items) is Counterbalance, wherein a very weak subject intentionally behaves in an aggressive manner both online and offline. The inability to face and combat the aggression suffered becomes a trigger for provocative and annoying behaviours. Adolescents' perception justifies others attacking the victim because she/he has had to deal with aggressive behaviour before, both face-to-face and online.

The third component (10 items) is Exclusion/Marginalisation and concerns people with low self-esteem and who are generally solitary. These people often experience difficult relationships in real life as well as online. The items making up this factor clearly address these issues. Some examples are: "He/she is a weak person", "He/she does not react when provoked", and "He/she has low self-esteem" (see Table 3).

For each component, mean scores were calculated, and bivariate linear correlations were computed using Pearson's $r$ coefficient. According to the findings (see Table 4) cybervictims are people with aggressive compensation behaviours and a depressive and degrading past. It is interesting to note that higher scores in Internalisation correlate with higher scores in Counterbalance and Marginalisation, with the latter being the stronger correlation.

To evaluate the discriminant validity of dimensions of the questionnaire highlighted in the PCA, the potential differences in these dimensions were assessed in relation to sociodemographic variables (gender) and personal experience of cyberbullying (addressed by the specific question in the protocol). Specifically, the differences among the means of the above-mentioned components were computed using a Multivariate Analysis of Covariance (MANCOVA) where the age of participants is a covariate, and the gender and personal experiences related to cyberbullying are factors (Tabachnick \& Fidell, 1996). As the vast majority of the subjects in the sample were unfamiliar with cyberbullying, a subgroup of subjects was randomly selected from those who had never experienced it, forming a control group to be compared with the three emerging subgroups: 1) cybervictims, 2) cyberbullies, and 3) both cybervictims and cyberbullies. Hence, the MANCOVA was computed based on a smaller number of participants $(N=103)$. The main effect of gender was found (Wilks' Lambda $\left.=.910, \mathrm{~F}_{(3,92)}=2.423, \mathrm{p}=.033\right)$. Furthermore, the main effect of the experience of cyberbullying was found (Wilks' Lambda $=.798, F_{(9,224)}=3.049, p=.012$ ). Age did not have a significant effect on scores. Tests of between-participants effects showed a significant effect on the experience of cyberbullying compared to Internalisation, where victims had higher scores than bullies and students without any such experience $\left(F_{(3,94)}=3.248, p=.025, \mu_{p}{ }^{2}=.094\right)$. Moreover, the significant effect of gender $\left(F_{(1 ; 94)}=\right.$ $4.908, p=.029, \mu_{p}^{2}=.050$ ) was observed in relation to Counterbalance, wherein males showed higher scores than females.

The following differences can be observed in the post-hoc comparisons (see Table 5) and charts (Figures 1 and 2). 
Table 3. Principal Component Analysis - Pattern Matrix

\begin{tabular}{|c|c|c|c|}
\hline & \multicolumn{3}{|c|}{ Component } \\
\hline & 1 & 2 & 3 \\
\hline Fear & .634 & -.159 & .035 \\
\hline Suicidal thought & .621 & -.177 & .123 \\
\hline Loss of appetite & .620 & .044 & -.037 \\
\hline Physical discomfort & .596 & .098 & .004 \\
\hline Difficult socialization & .588 & -.009 & .101 \\
\hline Low self-esteem & .585 & -.199 & .133 \\
\hline Problems at school & .584 & .026 & -.079 \\
\hline Committing suicide & .580 & -.170 & .110 \\
\hline Problems at home & .571 & .036 & -.022 \\
\hline Psychoactive substance abuse & .533 & .039 & -.026 \\
\hline Sadness & .496 & -.107 & .084 \\
\hline Problems with friends & .493 & .150 & .066 \\
\hline Shame & .479 & -.060 & .157 \\
\hline Feeling guilty & .479 & .024 & -.091 \\
\hline Aggressive behaviours toward friends & .445 & .195 & .087 \\
\hline Sleeplessness & .436 & .038 & -.096 \\
\hline How serious is it what happens to Anna & .370 & .054 & .010 \\
\hline $\mathrm{He} / \mathrm{she}$ is a bully in real life too & .058 & .713 & -.043 \\
\hline $\mathrm{He} / \mathrm{she}$ is a cyberbully too & .109 & .706 & -.179 \\
\hline $\begin{array}{l}\text { He/she has transgressive manners (aggressive episodes, alcohol or drug abuse, } \\
\text { break the law) }\end{array}$ & .163 & .661 & -.237 \\
\hline $\mathrm{He} /$ she is good at using $\mathrm{pc}$ and smartphones & -.024 & .547 & .145 \\
\hline Happiness & -.142 & .473 & .114 \\
\hline $\mathrm{He} /$ she knows his/her bullies in person & -.034 & .451 & .278 \\
\hline $\mathrm{He} / \mathrm{she}$ is a weak person & -.029 & -.039 & .747 \\
\hline $\mathrm{He} /$ she is shy & -.002 & -.277 & .711 \\
\hline $\mathrm{He} /$ she has low self-esteem & -.008 & -.165 & .692 \\
\hline $\mathrm{He} /$ she is a lonely person & .112 & .147 & .585 \\
\hline $\mathrm{He} /$ she has good school grades & .036 & -.258 & .508 \\
\hline It's because he/she doesn't react to incitements & .042 & .141 & .466 \\
\hline $\mathrm{He} / \mathrm{she}$ is a victim in face-to-face relationships too & .070 & .115 & .461 \\
\hline $\mathrm{He} / \mathrm{she}$ is not satisfied with his/her own life & .113 & .156 & .443 \\
\hline It's because he/she is different from other people & .247 & .008 & .354 \\
\hline His/her parents have strict rules about the use of Internet and smartphones & -.011 & .013 & .339 \\
\hline Cronbach's Alpha & .861 & .678 & .771 \\
\hline
\end{tabular}

Extraction Method: Principal Component Analysis. Rotation Method: Oblimin with Kaiser Normalization. Rotation converged in 11 iterations

Table 4. Pearson's correlation between means of components

\begin{tabular}{lccc}
\hline & C1- Internalization & C2 - Counterbalance & C3 - Marginalization \\
\hline C1 & 1 & & \\
C2 & $.126^{* *}$ & 1 & 1 \\
C3 & $.420^{* *}$ & .011 & \\
\hline$* * p<.001$ & & &
\end{tabular}

Table 5. Pairwise Comparisons - Bonferroni

\begin{tabular}{lccccc}
\hline Dependent Variable & Cyberbullying experience & Cyberbullying experience & Mean Difference & Std. Error & Sig \\
\hline Internalization & 1 victim & 2 bully & $.737^{*}$ & .285 & .011 \\
& & 3 both & .394 & .207 & .061 \\
& & 4 no experience & $.423^{*}$ & .194 & .032 \\
\hline
\end{tabular}

$* \mathrm{p}<.05$ 


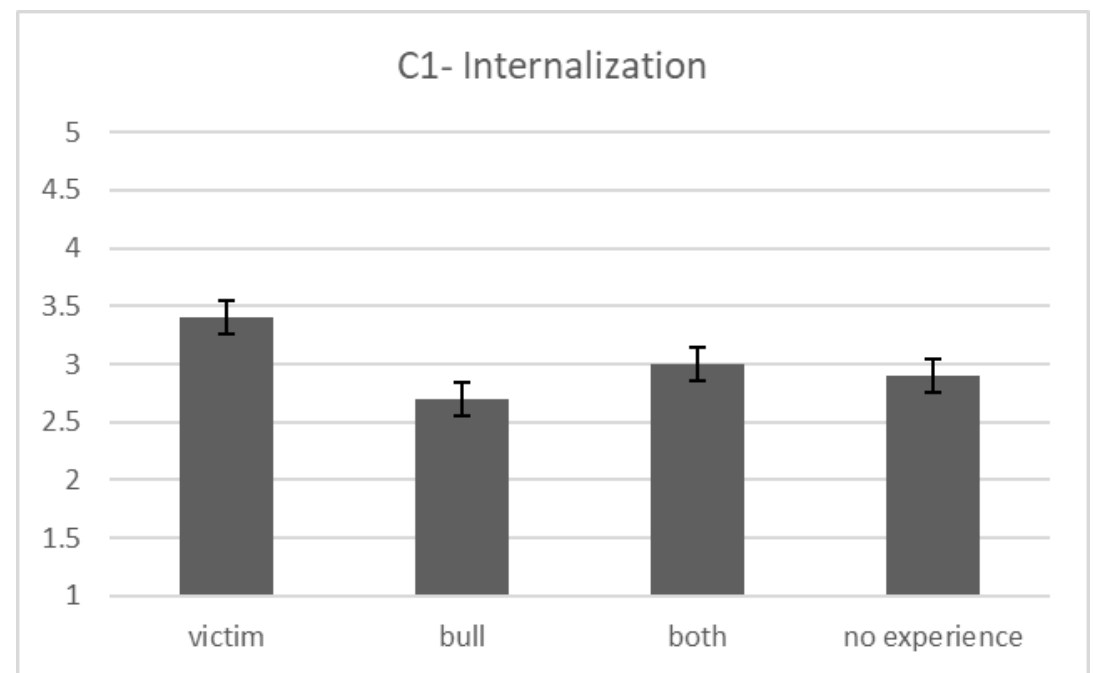

Figure 1. Means in the component Internalization in relation to the experience in cyberbullying

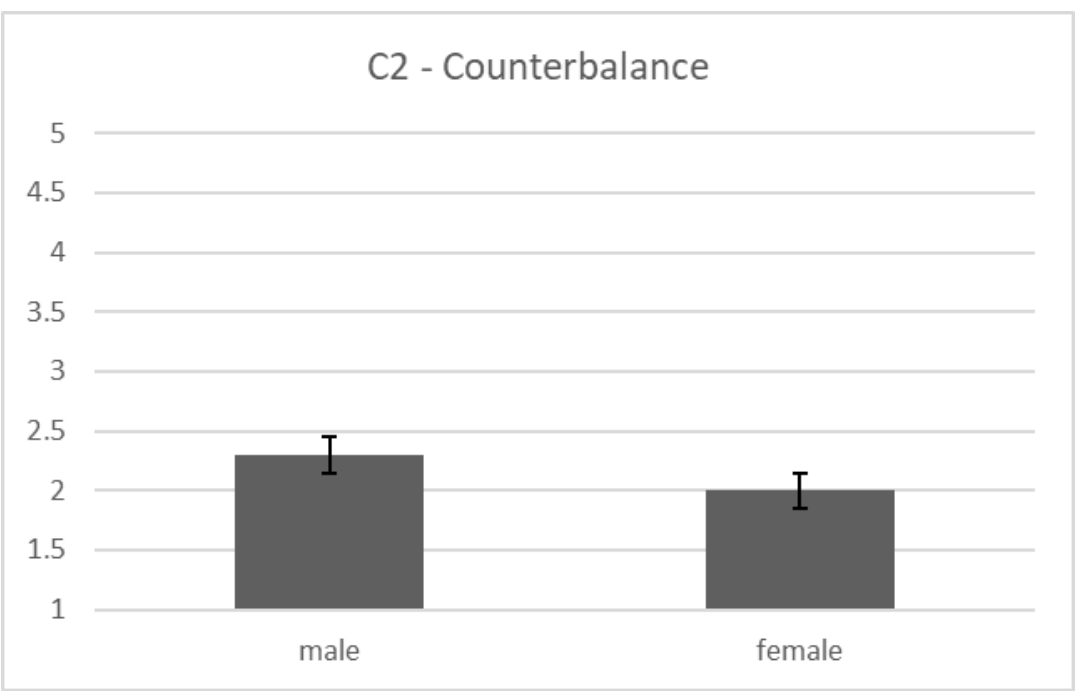

Figure 2. Means in the component Counterbalance in relation to the gender

\section{DISCUSSION}

This preliminary work of validation of the CVQ questionnaire had a twofold purpose.

The first aim was to create a tool to investigate the perception of cybervictims among adolescents and to assess their preliminary psychometric features.

The second aim was to provide fruitful information to plan and implement targeted interventions aimed at enhancing the affective empathy on cybervictims (Schultze-Krumbholz et al., 2016). In fact, the suffering that affects victims and the scarcity of bullies' and adolescents' awareness of their own responsibilities can have negative consequences and can enhance cyberbullying behaviour. That is why interventions focused on cultivating empathy-with the tools and strategies they provide to cope with the distress provoked by cyberbullying - could be a starting point to control this damaging phenomenon (Elipe et al., 2015).

This instrument, in this first step of the validation process, showed acceptable psychometric features in reliability and validity, at level of importance sufficient to encourage their further use and application in the educational contexts with adolescents. This questionnaire, which is designed for agile administration, might be useful for educators to enhance adolescents' awareness about the consequences of cyberbullying behaviour, and then, to combat the diffusion of cyberbullying. With the information obtained by questionnaire administration, educators might evaluate the situations in class and create the conditions to 
avoid the consequences of discriminatory cyberbullying (dangerously associated with depression, anxiety, low self-esteem, academic difficulties, self-harm behaviours, and suicidal thoughts). The current emergency linked to the spread of the phenomenon of cyberbullying requires educators to be able to make use of rapid screening tools, to assess possible adolescent discomfort, in order to report any critical situations to significant reference figures and to the school psychologist. Indeed, the exponential evolution of cyberbullying requires tailoring empirical ad hoc measures devoted to applying prevention strategies, combatting the phenomenon, and protecting and supporting adolescents in their fight against these challenges.

Previous research in the area of anti-cyberbullying programs has showed the direct correlation between depression and suicidal tendencies, stressing the importance of emotional and behavioural prevention in such contexts (Ansary, 2020; Beltrán-Catalán et al., 2018;). Social and emotional skills represent protective factors in cyberbullying. Hence, it is fundamental to structure intervention based on affective empathy and emotional contagion theory (Graf et al., 2019; Marín-López et al., 2020).

Cyberbullying victims are used to suffering from cyberbullying and, consequently, begin to believe that they deserve it. In some cases, they even blame themselves for what they endure, leading to the need to cope with shame and embarrassment (Ansary, 2020; Pereira et al., 2016). A situation of imbalance arises: the bully/cyberbully gets stronger while the victim is stuck in his/her position. Therefore, the aggressor adopts even more aggressive behaviours. Loneliness is a fundamental variable in many of these cases. Conflicting feelings create turmoil that is very difficult to alleviate (Heiman et al., 2018).

On the other hand, bullies/cyberbullies lack empathy, and their self-regulatory mechanisms are often poor: they cannot easily foresee the consequences of their actions, and they unconsciously opt for moral disengagement as a way to silence and disable self-condemnation, which is an important cognitive strategy that saves them from self-punishment and a loss of self-esteem (Brewer \& Kerslake, 2015). Some examples of how self-punishment is avoided are the dehumanisation of the victim, displacement and spread of responsibility, and the transfer of blame from oneself to the victim. In a sense, bullies/cyberbullies often hide their painful past: paradoxically, it is their own suffering that triggers the aggressive behaviour, uncovering the urgent need for intervention programs addressing both the victim and the aggressor. Indeed, as two sides of the same coin, they both need to develop emotional and affective intelligence for a healthier, happier, and more balanced relationship with themselves and others (Garaigordobil \& Martínez-Valderrey, 2015; Schoeps et al., 2018). According to Reniers and colleagues (2011), there are three subcomponents of affective empathy: emotional contagion, proximal responsivity and peripheral responsivity. Therefore, working on these three aspects is the key to driving people toward the comprehension of what being a victim means because only the real understanding of an issue can prevent people from making it happen (Elipe et al., 2015).

We have to highlight that this work has some limitations. In future research, it might be useful to administer the questionnaire to new participants to evaluate the data with a confirmative approach; furthermore it might be interesting to expand the assessment to include other relevant dimensions related to self-esteem, social intelligence, anxiety, empathy, and moral disengagement (Ansary, 2020).

\section{CONCLUSIONS}

It is becoming increasingly important to focus on the hidden aspects of violence by uncovering the pain experienced by victims so that aggressors can become conscious of the effects of their actions (Heiman \& Olenik-Shemesh, 2015). In narrowing the focus on cyberbullying, the weaker but more long-lasting effects of online violence must be stressed. This new form of perpetual, cunning harassment can increase suffering, which often goes unspoken (UN General Assembly, 2016). The instrument presented might improve personal reflection on cyberbullying, victims, and the consequences of these practices in the real lives of adolescents.

In summary, the instrument proposed might help teachers, educators, and professionals to immediately identify critical situations and to support adolescents' deep reflection on cyberbullying and its victims, supporting a more general understanding of the features of this phenomenon. 
Author contributions: All authors were involved in concept, design, collection of data, interpretation, writing, and critically revising the article. All authors approve final version of the article.

Funding: The authors received no financial support for the research and/or authorship of this article.

Declaration of interest: Authors declare no competing interest.

Data availability: Data generated or analysed during this study are available from the authors on request.

\section{REFERENCES}

Ansary, N. S. (2020). Cyberbullying: Concepts, theories, and correlates informing evidence-based best practices for prevention. Aggression and Violent Behavior, 50, 101343. https://doi.org/10.1016/j.avb.2019.101343

Aoyama, I. (2011). Cyberbullying: What are the psychological profiles of bullies, victims, and bully-victims? Dissertation Abstracts International Section A: Humanities and Social Sciences, 71, 3526. https://search.proquest.com/openview/21fbe068eeddf2e2d2385ca853bdc07c/1?pqorigsite $=$ gscholar\&cbl=18750\&diss $=y$

Barlett, C. P. (2017). From theory to practice: Cyberbullying theory and its application to intervention. Computers in Human Behavior, 72, 269-275. https://doi.org/10.1016/j.chb.2017.02.060

Beltrán-Catalán, M., Zych, I., Ortega-Ruiz, R., \& Llorent, V. J. (2018). Victimisation through bullying and cyberbullying: Emotional intelligence, severity of victimisation and technology use in different types of victims. Psicothema, 30(2), 183-188. https://doi.org/10.7334/psicothema2017.313

Brewer, G., \& Kerslake, J. (2015). Cyberbullying, self-esteem, empathy and loneliness. Computers in Human Behavior, 48, 255-260. https://doi.org/10.1016/j.chb.2015.01.073

Casas, J. A., Del Rey, R., \& Ortega-Ruiz, R. (2013). Bullying and cyberbullying: Convergent and divergent predictor variables. Computers in Human Behavior, 29(3), 580-587. https://doi.org/10.1016/j.chb.2012.11.015

Dredge, R., Gleeson, J., \& De la Piedad Garcia, X. (2014). Cyberbullying in social networking sites: An adolescent victim's perspective. Computers in human behavior, 36, 13-20. https://doi.org/10.1016/j.chb.2014.03.026

Elipe, P., Mora-Merchán, J. A., Ortega-Ruiz, R., \& Casas, J. A. (2015). Perceived emotional intelligence as a moderator variable between cybervictimization and its emotional impact. Frontiers in Psychology, 6(APR), 486. https://doi.org/10.3389/fpsyg.2015.00486

Garaigordobil, M., \& Martínez-Valderrey, V. (2015). The Effectiveness of Cyberprogram 2.0 on Conflict Resolution Strategies and Self-Esteem. Journal of Adolescent Health, 57(2), 229-234. https://doi.org/10.1016/j.jadohealth.2015.04.007

Graf, D., Yanagida, T., \& Spiel, C. (2019). Through the magnifying glass: Empathy's differential role in preventing and promoting traditional and cyberbullying. Computers in Human Behavior, 96, 186-195. https://doi.org/10.1016/j.chb.2019.02.007

Gross, E. F., Juvonen, J., \& Gable, S. L. (2002). Internet Use and Well-Being in Adolescence. Journal of Social Issues, 58(1), 75-90. https://doi.org/10.1111/1540-4560.00249

Heiman, T., \& Olenik-Shemesh, D. (2015). Cyberbullying Experience and Gender Differences Among Adolescents in Different Educational Settings. Journal of Learning Disabilities, 48(2), 146-155. https://doi.org/10.1177/0022219413492855

Heiman, T., Olenik-Shemesh, D., \& Liberman, G. (2018). Adolescent involvement in face-to-face and cyber victimization: can personal well-being mediate social-emotional behavior? Journal of Youth Studies, 21(3), 391-404. https://doi.org/10.1080/13676261.2017.1366650 
Huang, Y. Y., \& Chou, C. (2010). An analysis of multiple factors of cyberbullying among junior high school students in Taiwan. Computers in Human Behavior, 26(6), 1581-1590. https://doi.org/10.1016/j.chb.2010.06.005

Hinduja, S., \& Patchin, J. W. (2013). Social Influences on Cyberbullying Behaviors Among Middle and High School Students. Journal of Youth and Adolescence, 42(5), 711-722. https://doi.org/10.1007/s10964012-9902-4

Jain, O., Gupta, M., Satam, S., \& Panda, S. (2020). Has the COVID-19 pandemic affected the susceptibility to cyberbullying in India?. Computers in Human Behavior Reports, 2, 100029. https://doi.org/10.1016/j.chbr.2020.100029

Kowalski, R. M., Giumetti, G. W., Schroeder, A. N., \& Lattanner, M. R. (2014). Bullying in the digital age: A critical review and meta-analysis of cyberbullying research among youth. Psychological Bulletin, 140(4), 1073-1137. https://doi.org/10.1037/a0035618

Kowalski, R. M., Morgan, C. A., \& Limber, S. P. (2012). Traditional bullying as a potential warning sign of $\begin{array}{llll}\text { cyberbullying. School } & \text { Psychology International, 305-519. }\end{array}$ https://doi.org/10.1177/0143034312445244

Kraut, R., Patterson, M., Lundmark, V., Kiesler, S., Mukophadhyay, T., \& Scherlis, W. (1998). Internet paradox: A social technology that reduces social involvement and psychological well-being?. American psychologist, 53(9), 1017-1032.

Ladd, G. W., Ettekal, I., \& Kochenderfer-Ladd, B. (2017). Peer victimization trajectories from kindergarten through high school: Differential pathways for children's school engagement and achievement? Journal of Educational Psychology, 109(6), 826-841. https://doi.org/10.1037/edu0000177

Lareki, A., Altuna, J., Martínez de Morentin, J. I., \& Amenabar, N. (2017). Young people and digital services: Analysis of the use, rules, and age requirement. Children and Youth Services Review, 79(C), 126-131. https://doi.org/10.1016/j.childyouth.2017.06.002

Lereya, S. T., Samara, M., \& Wolke, D. (2013). Parenting behavior and the risk of becoming a victim and a bully/victim: A meta-analysis study. Child Abuse \& Neglect, 37(12), 1091-1108. https://doi.org/10.1016/j.chiabu.2013.03.001

Lozano-Blasco, R., Cortés-Pascual, A., \& Latorre-Martínez, P. (2020). Being a cybervictim and a cyberbullyThe duality of cyberbullying: A meta-analysis. Computers in Human Behavior, 106444. https://doi.org/10.1016/j.chb.2020.106444

Marchant, A., Hawton, K., Stewart, A., Montgomery, P., Singaravelu, V., Lloyd, K., ... John, A. (2017). A systematic review of the relationship between internet use, self-harm and suicidal behaviour in young people: The good, the bad and the unknown. PLOS ONE, 12(8), e0181722. https://doi.org/10.1371/journal.pone.0181722

Marín-López, I., Zych, I., Ortega-Ruiz, R., Hunter, S. C., \& Llorent, V. J. (2020). Relations among online emotional content use, social and emotional competencies and cyberbullying. Children and Youth Services Review, 108, 104647. https://doi.org/10.1016/j.childyouth.2019.104647

Menesini, E., \& Nocentini, A. (2009). Cyberbullying definition and measurement: Some critical considerations. Zeitschrift für Psychologie/Journal of Psychology, 217(4), 230-232. https://doi.org/10.1027/00443409.217.4.230

Mishna, F., Sanders, J. E., McNeil, S., Fearing, G., \& Kalenteridis, K. (2020). "If Somebody is Different": A critical analysis of parent, teacher and student perspectives on bullying and cyberbullying. Children and Youth Services Review, 118, 105366. https://doi.org/10.1016/j.childyouth.2020.105366 
Palladino, B. E., Menesini, E., Nocentini, A., Luik, P., Naruskov, K., Ucanok, Z., Dogan, A., Schultze-Krumbholz, A., Hess, M., \& Scheithauer, H. (2017). Perceived severity of cyberbullying: differences and similarities across four countries. Frontiers in Psychology, 8, 1524. https://doi.org/10.3389/fpsyg.2017.01524

Pereira, F., Spitzberg, B. H., \& Matos, M. (2016). Cyber-harassment victimization in Portugal: Prevalence, fear and help-seeking among adolescents. Computers in Human Behavior, 62, 136-146. https://doi.org/10.1016/j.chb.2016.03.039

Renati, R., Berrone, C., \& Zanetti, M. A. (2012). Morally disengaged and unempathic: Do cyberbullies fit these definitions? An exploratory study. Cyberpsychology, Behavior, and Social Networking, 15(8), 391-398. https://doi.org/10.1089/cyber.2012.0046

Reniers, R. L., Corcoran, R., Drake, R., Shryane, N. M., \& Völlm, B. A. (2011). The QCAE: A questionnaire of cognitive and affective empathy. Journal of personality assessment, 93(1), 84-95. https://doi.org/10.1080/00223891.2010.528484

Sabella, R. A., Patchin, J. W., \& Hinduja, S. (2013). Cyberbullying myths and realities. Computers in Human Behavior, 29(6), 2703-2711. https://doi.org/10.1016/j.chb.2013.06.040

Şahin, M., Aydin, B., \& Sari, S. V. (2012). Cyber bullying, cyber victimization and psychological symptoms: A study in adolescents. Cukurova University Faculty of Education Journal, 41(1), 53-59. http://egitim.cu.edu.tr/efdergi

Schoeps, K., Villanueva, L., Prado-Gascó, V. J., \& Montoya-Castilla, I. (2018). Development of emotional skills in adolescents to prevent cyberbullying and improve subjective well-being. Frontiers in psychology, 9, 2050. https://doi.org/10.3389/fpsyg.2018.02050

Schultze-Krumbholz, A., Schultze, M., Zagorscak, P., Wölfer, R., \& Scheithauer, H. (2016). Feeling cybervictims' pain-The effect of empathy training on cyberbullying. Aggressive behavior, 42(2), 147156. https://doi.org/10.1002/ab.21613

Selkie, E. M., Fales, J. L., \& Moreno, M. A. (2016). Cyberbullying prevalence among US middle and high schoolaged adolescents: A systematic review and quality assessment. Journal of Adolescent Health, 58(2), 125-133. https://doi.org/10.1016/j.jadohealth.2015.09.026

Shaheen, A. M., Hamdan, K. M., Albqoor, M., Othman, A. K., Amre, H. M., \& Hazeem, M. N. A. (2019). Perceived social support from family and friends and bullying victimization among adolescents. Children and Youth Services Review, 107, 104503. https://doi.org/10.1016/j.childyouth.2019.104503

Tabachnick, B. G., \& Fidell, L. S. (1996). Using Multivariate Statistics (3rd ed.). HarperCollins.

Twenge, J. M., Spitzberg, B. H., \& Campbell, W. K. (2019). Less in-person social interaction with peers among US adolescents in the 21st century and links to loneliness. Journal of Social and Personal Relationships, 36(6), 1892-1913. https://doi.org/10.1177/0265407519836170

UN General Assembly. (2016). Protecting children from bullying. Report of the Secretary-General, 12907(July). $\quad$ http://srsg.violenceagainstchildren.org/sites/default/files/documents/docs/A-71-

213_EN.pdf

Wang, L., \& Ngai, S. S. Y. (2020). The effects of anonymity, invisibility, asynchrony, and moral disengagement on cyberbullying perpetration among school-aged children in China. Children and Youth Services Review, 119, 105613. https://doi.org/10.1016/j.childyouth.2020.105613

Wang, X., Yang, J., Wang, P., \& Lei, L. (2019). Childhood maltreatment, moral disengagement, and adolescents' cyberbullying perpetration: Fathers' and mothers' moral disengagement as moderators. Computers in Human Behavior, 95, 48-57. https://doi.org/10.1016/j.chb.2019.01.031 
Watts, L. K., Wagner, J., Velasquez, B., \& Behrens, P. I. (2017). Cyberbullying in higher education: A literature review. Computers in Human Behavior, 69, 268-274. https://doi.org/10.1016/j.chb.2016.12.038

Ybarra, M. L., \& Mitchell, K. J. (2004). Youth engaging in online harassment: Associations with caregiver-child relationships, Internet use, and personal characteristics. Journal of adolescence, 27(3), 319-336. https://doi.org/10.1016/j.adolescence.2004.03.007

Zych, I., Ortega-Ruiz, R., \& Del Rey, R. (2015). Systematic review of theoretical studies on bullying and cyberbullying: Facts, knowledge, prevention, and intervention. Aggression and Violent Behavior, 23, 121. https://doi.org/10.1016/j.avb.2015.10.001

Correspondence: Maria Lidia Mascia, Department of Pedagogy, Psychology, Philosophy, Faculty of Humanistic Studies, University of Cagliari, Italy. E-mail: marialidia.mascia@unica.it 